\title{
Educação Especial e avaliações em larga escala no município de Sobral (CE)
}

\author{
Ana Paula Lima Barbosa Cardoso* \\ Rita de Cássia Barbosa Paiva Magalhães**
}

\section{Resumo}

Este artigo objetiva discutir e analisar a participação dos alunos com deficiência da rede pública de ensino do município de Sobral-CE nos processos de avaliação em larga escala desenvolvidos naquele contexto. Decorre de um estudo de caso, de abordagem qualitativa, realizado no âmbito da Secretaria de Educação municipal e em duas escolas, de maior e menor resultados no IDEB (2009). Os instrumentos de coleta de dados: análise de documentos, entrevista e observação; e como procedimento de tratamento, a análise de conteúdo. O referencial teórico discute a avaliação em larga escala no contexto brasileiro em articulação com a literatura sobre a avaliação dos processos de ensino destinados aos alunos com deficiência. São descritos o panorama da educação sobralense em geral e, ainda, dados sobre a educação especial. Os resultados da investigação discutem dois processos de avaliação em larga escala ocorridos naquela municipalidade: avaliação municipal e a Prova Brasil. No tocante ao primeiro, os sujeitos da pesquisa afirmam a participação dos alunos com deficiência mediante um mecanismo que impede que os resultados desses alunos prejudiquem os demais; são as denominadas "crianças da margem". Na Prova Brasil, os sujeitos informaram novamente a participação desses alunos no teste nacional. Criticaram a adequação daquele instrumento para avaliar esse alunado específico, sugerindo a necessidade de desenvolvimento de instrumentos mais "pertinentes". Por fim, infere-se que a avaliação em larga escala coloca em xeque o processo de escolarização vivenciado pelo alunado com deficiência de Sobral-CE, mostrando os desafios e dificuldades das ações de inclusão escolar propostas naquela rede.

Palavras-chave: Educação especial; Avaliação em larga escala; Educação inclusiva.

\footnotetext{
* Professora na Universidade Estadual do Ceará, Doutoranda em Educação na Universidade Federal do Ceará (UFC), Fortaleza, Ceará.

** Professora Doutora da Universidade Federal do Rio Grande do Norte (UFRN). Docente do Programa de Pós-Graduação em Educação da UFRN. Natal, Rio Grande do Norte.
} 


\section{Special educaction and rewiews in the municipality of large scale Sobral (CE)}

\section{Abstract}

This article aims to discuss and analyze the participation of students with disabilities in public schools of the city of Sobral-CE in the assessment scale developed in that context. It follows a case study, a qualitative approach, conducted within the Department of Education and two municipal schools; the highest and lowest IDEB results (2009). The data collection instruments: analysis of documents, interviews and observation, and content analysis. The theoretical framework discusses the large-scale evaluation in the brazilian context in conjunction with the literature on the evaluation of teaching for students with disabilities. We describe the landscape of education in general sobralense and also data on special education. The research results discussed two cases of large-scale evaluation that occurred in that municipality: municipal evaluation and Proof Brazil. Regarding the first, the subjects affirms the participation of students with disabilities through a mechanism that prevents these results affect other students, are called "children of the shore." In Proof Brazil, the subjects again reported the participation of these students in national testing. It's criticizing the appropriateness of that instrument to assess this particular student body, suggesting the need of developping more "relevant" ones. Finally, it appears that the large-scale evaluation calls into question the process of schooling experienced by pupils with disabilities in Sobral-CE, showing the challenges and difficulties of the actions of school inclusion proposals in that context.

Keywords: Special education; Evaluation on a large scale; Inclusive education

Avaliações em larga escala são procedimentos amplos e extensivos dirigidos aos sistemas educacionais. São encomendados pelas instâncias de governo para os gestores educacionais verem fotografados aspectos gerais de suas redes de ensino. Estes processos, na educação básica brasileira, devem fornecer dados de desempenho sobre totalidade dos alunos, inclusive aqueles que apresentam singularidades. Mas em que medida estas avaliações coletam informações sobre os alunos com deficiência matriculados? Como ocorre a participação destes alunos neste processo considerando suas dificuldades de acesso e permanência?

O objetivo deste artigo é, então, discutir e analisar a participação dos alunos com deficiência nos processos de avaliação em larga escala desenvolvidos na rede municipal de ensino no município de Sobral-CE. 
Este texto foi organizado da seguinte forma: inicialmente, analisamos o modo de organização da avaliação em larga escala no contexto brasileiro e suas implicações para os alunos com deficiência inseridos na escola; na sequência apresentamos a metodologia da investigação para, a seguir, serem apresentados os resultados do estudo realizado seguidos de considerações finais.

Avaliação em larga escala no contexto brasileiro: um processo "inclusivo"?

As iniciativas de avaliação dos sistemas emergiram no Brasil na década de 1990, quando o Governo Federal passou a organizar sistemas de avaliação, sob a justificativa de subsidiar a elaboração de diagnósticos sobre a realidade educacional e orientar a elaboração de políticas com vistas à melhoria da qualidade do ensino. Governos estaduais, na mesma lógica, elaboraram sistemas próprios de avaliação, complementando os de âmbito federal.

$\mathrm{Na}$ avaliação da educação básica brasileira, destacam-se o Sistema de Avaliação da Educação Básica (SAEB) e o Exame Nacional do Ensino Médio como iniciativas do Governo federal. Em 2005, o SAEB foi objeto de modificações, passando a constituir-se de duas avaliações: a Avaliação Nacional da Educação Básica (Aneb), realizada por amostragem e na gestão das redes de ensino; e a Avaliação Nacional do Rendimento Escolar (Anresc), conhecida como Prova Brasil, de base censitária.

Esta estrutura começou a ser organizada no curso do segundo mandato de Lula (2007-2010), no qual foram conferidos novos contornos à avaliação da educação do país, através da criação do Índice de Desenvolvimento da Educação Básica (IDEB).

O IDEB é um indicador objetivo de verificação do cumprimento das metas fixadas no Termo de Adesão ao Compromisso "Todos pela Educação" - um dos eixos do Plano de Desenvolvimento da Educação (PDE) para a educação básica (CASTRO, 2010) - que combina dois índices usualmente utilizados para monitorar os sistemas de ensino: dados de fluxo escolar (promoção, repetência e evasão), e o desempenho dos alunos nas avaliações do INEP. Seu cálculo se baseia em dados de aprovação do Censo Escolar e nas médias de desempenho obtidas nas avaliações nacionais: SAEB, para as unidades da federação e para o país; e a Prova Brasil, para os municípios (BRASIL, 2007). 
Em suma, o IDEB faz parte de uma iniciativa de estabelecimento de critérios e modelos para monitoramento do sistema de ensino no Brasil, ou seja, de mensurar a qualidade da educação. O índice foi instituído como indicador da qualidade da educação, contudo não parece apresentar os requisitos fundamentais capazes de aferir com eficácia os níveis de qualidade do ensino brasileiro. Assim, vem recebendo críticas:

[...] questionado por educadores, pesquisadores e estudiosos, os quais argumentam que é preciso considerar o processo e não apenas medir o resultado através dos dados sobre aprovação escolar, obtidos no censo escolar, e as médias de desempenho em avaliações do INEP. (grifamos) (CAMINI, 2010, p. 545)

Oliveira (2007) não se opõe ao estabelecimento de indicadores objetivos para o processo educacional, mas identifica um "problema" na medida em que este índice é tratado como um indicador de qualidade, isto é, a crítica repousa no fato de o IDEB, como produto, ser a medida da qualidade da educação brasileira.

Os sistemas de avaliação da atualidade apresentam as seguintes características, segundo Sousa $(2009$, p. 34): "ênfase nos produtos ou resultados; atribuição de mérito a alunos, instituições ou redes de ensino; dados de desempenho escalonados, resultando em classificação; dados predominantemente quantitativos; destaque à avaliação externa não articulada à autoavaliação". Também a prática da divulgação dos resultados das avaliações por meio de rankings é uma peculiaridade deste processo que dá margem à "classificação e da seleção incorporam, consequentemente, a exclusão, como inerente aos seus resultados, o que é incompatível com o direito de todos à educação". (SOUSA, 2009, p. 34).

As avaliações desenvolvidas nos moldes do SAEB e Prova Brasil sugerem mecanismos excludentes, pautados na competição entre sistemas e escolas, e até entre os alunos. O princípio adotado - esclarece Sousa (2009) - é o de que a avaliação inspira competição, e a competição propicia qualidade.

Iniciativas como a Prova Brasil e o IDEB procuram estabelecer a qualidade da educação por meio da responsabilização das escolas e municípios. A ideia subjacente é de que, por meio dos rankings, por comparação, os gestores assegurariam a melhoria da qualidade do ensino. A responsabilização, entretanto, mascara a realidade porque imputa às escolas e às redes de ensino atribuições que são de ofício do Estado brasileiro, por meio das políticas sociais. 
[...] os testes padronizados são instrumentos necessários, mas insuficientes para avaliar a melhoria da qualidade da educação (...), pois possuem um caráter restrito de avaliação. É importante considerar, nesse processo, não só os insumos, mas também outros indicadores como a cultura organizacional da escola, as práticas e as relações entre professores e alunos. (CASTRO, 2009, p. 34)

A autora, ancorada em Silva (1996), propõe uma concepção democrática de qualidade da educação, afirmando-a relacional, substantiva, política e histórica. Esta perspectiva de análise implica, pois, a mudança da ideia de responsabilização - própria das avaliações de larga escala - para uma visão de participação e envolvimento local nas decisões da escola.

O seguinte questionamento se impõe: Os alunos que se apresentam a exame, os que fazem a Prova Brasil, por exemplo, não tiveram, todos, as mesmas oportunidades de sucesso escolar. Como podem, então, ser submetidos à mesma verificação, e seus resultados podem ser o principal instrumento de aferição da qualidade da educação do país? Os processos de ensino não são iguais nas diferentes escolas, os alunos também não são iguais, e muito menos suas condições materiais de escolarização.

Critérios utilizados nas avaliações para aferir a qualidade da educação, ensina Cabrito (2009), devem ser amplos, de ordem quantitativa e também qualitativa. Estes últimos podem, inclusive, ser diferentes de escola para escola, devendo apresentar o maior número possível de indicadores de contexto, a fim de possibilitar uma realidade bem espelhada do que é avaliado.

No sistema de avaliação atual encontram-se todos os alunos da escola, inclusive àqueles com deficiência? Esta questão foi o mote inicial de nossas reflexões em torno da temática.

Podemos afirmar que estamos diante de um objeto ainda pouco investigado no campo da educação especial de perspectiva inclusiva. A dissertação defendida por Monteiro (2010) aponta, por intermédio de um estudo exploratório realizado em cinco municípios da Baixada Santista-SP, que a inclusão está distante de se materializar sob esse aspecto, e que para que a Prova Brasil alcance todos os alunos, o teste deve garantir a igualdade de condições de participação e atendimento às pessoas com deficiência. 
A despeito da escassez de literatura sobre o tema, pesquisadores como Beyer, (2004); Oliveira e Campos (2005); Fernandes e Viana (2010) detiveram-se nas especificidades do processo de avaliação da aprendizagem de pessoas com deficiência.

A avaliação da aprendizagem é compreendida neste estudo como elemento fundamental para direcionar a prática pedagógica baseada nos resultados dos alunos. Quando se trata de alunos com deficiência inseridos na escola comum, a avaliação deve assumir as seguintes características: ser processual, contínua e dinâmica.

Beyer (2004) refere como finalidade principal dessa avaliação a análise das potencialidades de desenvolvimento e aprendizagem do aluno com deficiência, atentando, ainda, para as mudanças na prática educativa, necessárias à sua aprendizagem.

Postulamos o argumento de que os primeiros passos de enfrentamento dessa questão não devem ser atribuição das escolas, ocorrendo de forma focalizada, portanto. As iniciativas devem situar-se no âmbito dos sistemas de ensino, com a elaboração de políticas avaliativas específicas aos alunos com deficiência. Estas devem se constituir com dois focos: na escola, com instrumental amplo que possibilite a avaliação de aprendizagem; nos sistemas de ensino: por meio de processos que mapeiem a aprendizagem desses alunos como um todo, preservando, contudo, suas especificidades. A tarefa exige atitude dialética ao visualizar esse todo, sem perder de vista as peculiaridades de alunos com níveis de desenvolvimento e aprendizagem amplamente diversificados. Reafirmamos que nosso objetivo neste artigo é discutir e analisar a participação dos alunos com deficiência nos processos de avaliação em larga escala desenvolvidos na rede municipal de Sobral-CE.

\section{Percursos Metodológicos}

A investigação ancorou-se na abordagem qualitativa, viabilizada por meio do estudo de caso, segundo Stake (1998), André (2005), Minayo (2008) e Martins (2008). Os estudos de caso em educação devem apresentar um engenhoso recorte de uma situação complexa do contexto educacional real, cuja análise-síntese dos achados tem a possibilidade de surpreender, revelando perspectivas que não tinham sido abordadas em estudos semelhantes (MARTINS, 2008). O caso em estudo foi investigar participação dos alunos com deficiência nos processos de avaliação em larga escala desenvolvidos na rede municipal de ensino em Sobral-CE. Isto foi realizado articulando políticas educação especial de Sobral-CE em sua relação com 
as iniciativas de avaliação em larga escala realizadas naquele contexto. Os instrumentos de coleta de dados foram a análise documental, a entrevista e a observação.

O estudo foi realizado no município de Sobral-CE. Na primeira parte da pesquisa foram sujeitos o Secretário de Educação e quatro técnicas no âmbito da Secretaria Municipal de Educação (SME). A segunda parte do estudo foi realizada em duas escolas: de maior e menor IDEB (denominadas escolas A e B), sendo sujeitos em cada uma delas o diretor, coordenador pedagógico e professor da sala de aula regular (com alunos com deficiência incluídos) e de Atendimento Educacional Especializado (AEE). Ao final, foram sujeitos do estudo, 13 profissionais daquela rede.

Os dados foram tratados por intermédio da análise de conteúdo (BARDIN, 1977; FRANCO, 2005), ensejando a discussão a seguir desenvolvida.

\section{Educação em Sobral: contexto em análise}

O Município de Sobral está localizado a noroeste do Ceará, distante 206 km da Capital, Fortaleza. Possui uma população de 188.233 habitantes e ocupa o $5^{\circ}$ lugar no PIB cearense. O município se destaca pela continuidade político-administrativa, pois desde os anos 2000 é administrada pelo mesmo grupo político .

O município conta com uma rede própria de ensino que atende a educação infantil (creche e pré-escola) e ensino fundamental ( $1^{\circ}$ a $9^{\circ}$ ano), e modalidades de educação de jovens e adultos (EJA) e educação especial. Sobral instituiu o ensino fundamental com duração de nove anos desde 2001. Há uma peculiaridade na oferta desse nível, pois o município é um dos poucos do Ceará que ainda possui alunos do ensino fundamental na rede estadual.

De acordo com o Censo Escolar 2010, a rede municipal de Sobral mantém 36 escolas urbanas e 24 escolas rurais, totalizando 60 estabelecimentos de ensino. As matrículas da rede municipal pública (rural e urbana) no ensino fundamental perfazem o montante de 24.750 , destacandose no universo de matrículas daquele município que é de 64.632 . 
Os indicadores educacionais do ensino fundamental em 2010 informam as seguintes taxas: $97,3 \%$ de aprovação, $2,5 \%$ de reprovação e $0,2 \%$ de abandono. À luz dos percentuais do Estado (aprovação, 88,4\%; reprovação, $8,7 \%$; e abandono, $2,9 \%$ ), a rede sobralense aprova mais alunos e, consequentemente, tem menores taxas de reprovação e abandono.

Em relação aos resultados no IDEB, alcançou 4,0 pontos em 2005, 4,9 em 2007 e 6,6 em 2009 , superando a meta prevista para 2021 que era 6,1. Nos anos de 2005, 2007 e 2009, desta feita; Sobral superou os resultados do Ceará que foram de 3,2, 3,5 e 4,2, respectivamente. O secretário de Educação atribui esse resultado às ações de alfabetização praticada no Município, "pois se você retroagir o menino do quinto ano de 2005 ele era justamente o menino do primeiro ano em 2002, que passou por toda a nossa política de alfabetização desde 2002".

No tocante à Educação Especial foi fundada, em 1990, a APAESobral, em pleno início das discussões sobre a perspectiva inclusiva nos sistemas escolares mundiais. Atualmente, a escolarização desses alunos é predominantemente de perspectiva inclusiva, conforme informa o quadro a seguir.

\begin{tabular}{|c|c|c|c|c|c|c|c|c|c|c|}
\hline \multirow{3}{*}{ 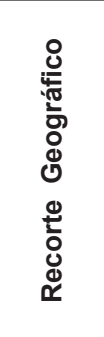 } & \multirow{3}{*}{ Rede } & \multicolumn{9}{|c|}{ Ensino Fundamental - 2010} \\
\hline & & \multicolumn{3}{|c|}{ Inclusão } & \multicolumn{3}{|c|}{$\begin{array}{l}\text { Classes } \\
\text { Especial/ } \\
\text { Exclusiva } \\
\text { Especial }\end{array}$} & \multicolumn{3}{|c|}{ Geral } \\
\hline & & $\begin{array}{l}5^{\circ} \\
\text { Ano }\end{array}$ & $\begin{array}{c}1^{\circ} \mathrm{ao}^{\circ} \\
5^{\circ}\end{array}$ & $\begin{array}{c}\text { Total } \\
1\end{array}$ & $\begin{array}{l}5^{\circ} \\
\text { Ano }\end{array}$ & $\begin{array}{l}1^{\circ} \\
\text { ao } \\
5^{\circ}\end{array}$ & $\begin{array}{c}\text { Total } \\
2\end{array}$ & $\begin{array}{l}5^{\circ} \\
\text { Ano }\end{array}$ & $\begin{array}{l}1^{\circ} \\
\text { ao } \\
5^{\circ}\end{array}$ & $\begin{array}{l}\text { Total } \\
1+2\end{array}$ \\
\hline \multirow{5}{*}{ Sobral } & Estadual & 0 & 0 & 31 & 0 & 0 & 0 & 0 & 0 & 31 \\
\hline & Municipal & 118 & 636 & 868 & 5 & 15 & 17 & 123 & 651 & 885 \\
\hline & Pública & 118 & 636 & 899 & 5 & 15 & 17 & 123 & 651 & 916 \\
\hline & Particular & 2 & 13 & 15 & 12 & 44 & 88 & 14 & 57 & 103 \\
\hline & Total & 120 & 649 & 914 & 17 & 59 & 105 & 137 & 708 & 1019 \\
\hline
\end{tabular}

Quadro 1. Matrículas da "Inclusão" e Classes e Escolas Especiais nos primeiros anos do Ensino Fundamental, nas redes públicas e privada de Sobral-CE. SEDUC, 2010.

Inferimos que o atendimento aos alunos com deficiência nos primeiros anos do ensino fundamental é predominantemente público, municipal e realizado através da perspectiva inclusiva. Segundo a SME, 
em todas as escolas há alunos com deficiência matriculados. No caso em exame, investigamos duas escolas da rede: a de maior (escola $A$ ) e de menor (escola B) IDEB (2009). A escola A alcançou 7,6 no índice, e a escola B, 5,3.

A análise comparativa permite concluir que há diferenças significativas entre as duas escolas. A escola A localiza-se na zona urbana, em terreno amplo e possui grupo de docentes que se relacionam de forma cooperativa; a escola B, por sua vez, situa-se na zona urbana, a $35 \mathrm{~km}$ da sede, está assentada em terreno de pequenas dimensões, apresenta infraestrutura precária e o destaque positivo parece ser núcleo gestor, um grupo aparentemente comprometido com o trabalho escolar. Também o AEE realizado nas duas escolas tem particularidades: na escola $A$ há sala para 0 atendimento, enquanto na escola B inexiste espaço para essa atividade. Há, porém, professor especializado nas duas escolas.

A Secretaria de Educação sobralense possui uma "Coordenação do AEE" que se ocupa da formulação e implementação de iniciativas voltadas aos alunos com deficiência daquela rede.

Avaliações em larga escala e os alunos da Educação Especial: a visão dos gestores educacionais, escolares e professores

No município de Sobral coexistem três processos de avaliação: a Avaliação Externa Municipal, o SPAECE e a ANRESC, conhecida como Prova Brasil.

Iniciamos pelo processo de Avaliação Externa Municipal por duas razões: sua importância na política educacional local, e por ter sido inaugurada em 2001, anterior, portanto, à primeira edição da Prova Brasil (2005). A premissa é de que, por ser uma elaboração própria e mais "madura" em relação à avaliação nacional, haja mais apropriação dos sujeitos sobre ela.

Desde o início da implementação da Avaliação Municipal, os alunos com deficiência participaram do processo. Os que possuíam laudos médicos atestando sua deficiência, contudo, tinham seus resultados "não contabilizados", afirmou o Secretário. Atualmente, o desempenho desses alunos nas provas é "levado em consideração", com base em um mecanismo de gestão criado pela SME que Ihes confere tratamento específico:

Avaliadas elas [crianças com deficiência] sempre foram. Elas não eram contabilizadas no resultado, na consolidação da avaliação. Todas as crianças, todas,

Revista Educação Especial | v. 25 | n. 44, | p. 449-464 | set./dez. 2012

Santa Maria

Disponível em: <http://www.ufsm.br/revistaeducacaoespecial> 
desde o início desse "projeto" [projeto de educação de Sobral], todas as séries que foram objeto de avaliação foram avaliadas. (...)(Secretário de Educação)

Atualmente os resultados de desempenho desses alunos nos testes são "contabilizados" através de um mecanismo de gestão criado pela SME e explicitado por seu gestor:

Existe uma margem que a escola tem para se situar no resultado desejado. Por exemplo, quando a gente baixa nosso edital [de premiação ] coloca sempre assim: a escola que alcançar $95 \%$ ou $90 \%$ de alfabetização, por exemplo, deverá ser premiada. Então ela terá uma margem de $10 \%$ ou de $5 \%$ [...] A gente percebe que na margem, nesse residual, tem vários desses alunos que são especiais [...]

Os gestores de Sobral criaram, então, uma forma de lidar com os alunos com deficiência. Inspirados na nomenclatura utilizada pela SME, denominamos estes alunos, em nossos estudos, de "crianças da margem". Alunos que por pretextos constitutivos variados, que podem estar ligados à deficiência ou mesmo a problemas de aprendizagem, não atendem aos padrões homogêneos, estanques e fixos exigidos pelas avaliações em larga escala (SOUSA, 2009).

A participação dos alunos com deficiência na Avaliação Municipal foi referida pelo secretário e técnicos da SME, e pelos diretores, coordenadores e professores das escolas A e B. Mas "de que maneira" participam esses alunos?

Eles participam normalmente da avaliação (...) A avaliadora externa chega na escola, confere a lista de alunos, e vai à sala de aula. É aplicada a avaliação normalmente. A gente apenas diz: 'Olha a aluna ' $X$ ' é considerada aluna especial'. Ela [aplicadora] registra lá, mas ela [aluna com deficiência] entrega a avaliação normalmente, procedimento normal da avaliação externa. (Diretor escola A)

A dinâmica avaliativa anunciada pelo Diretor da escola A perde a característica de processo banal, habitual e sem peculiaridades diante dos relatos da coordenadora do $5^{\circ}$ ano daquela escola.

Os alunos participam, mas é assim... A gente ensina mais ou menos a marcar[...] Eu ensinei: em cada prova tu marca uma questão; ou tu marca a "A", ou a "B" ou a 
"C". Porque a ' $X$ ' é uma das que cobra muito se não vier prova pra ela. Se não vier uma prova pra ela, ela fica indignada. E diz: 'Tia, eu vou fechar a prova, eu vou!'. É engraçado... (Coordenadora escola A)

A situação exposta é controversa e passível de variados entendimentos. A aluna citada tem 13 anos, e está regularmente matriculada no $5^{\circ}$ ano de uma escola regular da rede de ensino. Seu nome consta na relação dos alunos que devem, naquela oportunidade, ser avaliados. Ela recebe a prova, mas não sabe lê-la. Responde, então, de forma aleatória todo o teste, sem o entendimento real do que faz. Uma coisa a move: o desejo de participar daquele processo junto com seus pares, os demais alunos. Então, nos perguntamos: Aquele teste (que pode ser de Português ou Matemática, tanto faz) tem a possibilidade de aferir algo que foi ensinado àquela aluna em algum momento de sua escolarização? Podemos afirmar que a aluna participa do processo avaliativo relatado? Ou mesmo do processo educativo avaliado?

$\mathrm{Na}$ escola $\mathrm{B}$, o relato da coordenadora sobre a avaliação em uma turma de $5^{\circ}$ ano retrata uma situação similar à ocorrida na escola $\mathrm{A}$, mas com nuanças diferentes.

Essa semana eu tava até comentando com o Diretor sobre a provinha do ' $X$ '... Eu estava passando pela porta das salas, e o ' $X$ ' levantou a prova dele e falou assim: 'Tia eu fiz minha prova, olha só!'. Aí eu vi uma seqüência de círculos na prova dele, círculos que iam do início até o fim da linha, com uma estrutura como se fosse um texto pra ele. Percebi que era o jeito dele escrever. Então eu falei pro Diretor que ele [aluno com deficiência] teve uma evolução nessa parte [da escrita]. Porque na avaliação do ano passado ele rabiscou tudo, de cima a baixo, fez um carvão na prova dele, ficou tudo preto. Então nessa questão a gente vê que já tá melhorando, por mais que outras pessoas não percebam, é uma evolução, pra gente é. (Coordenadora escola B)

A avaliação realizada naquele contexto tinha ênfase nos resultados dos alunos avaliados, estes passíveis de escalonamento (SOUSA, 2009). O processo revelou-se excludente, pois foi incapaz de alcançar o que a coordenadora denominou de "evolução" daquele aluno. Ela percebeu que o aluno, baseado nas estruturas cognitivas que possuía, conseguiu externar o avanço de seu processo de escrita em alguma medida. Inferimos que, registrando "bolinhas" no espaço designado para a produção de texto (prova de redação), o aluno evidenciou seus primeiros níveis de escrita, como ensina Ferreiro (2001). 
A lógica das avaliações de larga escala que é "a avaliação gera competição, e a competição gera qualidade", produz exclusão em tempos de inclusão. A responsabilização dos professores pelos resultados parece inviabilizar os pressupostos básicos da prática pedagógica inclusiva na escola da atualidade. É o que sugerem as professoras de $5^{\circ}$ ano das escolas A e B de Sobral-CE.

No que diz respeito participação de alunos com deficiência na Prova Brasil, teste padronizado aplicado nacionalmente e que compõe o IDEB - o secretário relatou:

Quando são de caráter externo a Sobral, como por exemplo, a Provinha Brasil, o SPAECE, a Prova Brasil, aí não tem jeito. A gente se esforça muito para avaliar $100 \%$. A gente monta um esquema de guerra para avaliar todas. (Secretário de Educação de Sobral)

$\mathrm{Na}$ sequência, afirmou que "todos os alunos em 2009 foram avaliados pela Prova Brasil, inclusive aqueles tidos como alunos especiais [alunos com deficiência]". O núcleo gestor e professores das escolas A e B confirmaram a participação dos alunos com deficiência no teste nacional. A professora do $5^{\circ}$ ano da escola $A$, entretanto, referindo-se a uma de suas alunas, informou que esta não participou do teste porque não fica em sala de aula.

As impressões do secretário sobre a Prova Brasil merecem destaque e discussão. O gestor inicia apontando as "deficiências" e inadequação dos testes "estandardizáveis" para os alunos com deficiência.

Eles [alunos com deficiência] são considerados [pausa] sem a devida precisão que precisaria ter um instrumento para avaliar esses alunos. Ou seja, a Prova Brasil não dá conta do crescimento, da formação dessas crianças. Como qualquer outra avaliação nesse momento que fosse institucionalizada e sistêmica (...) Então ela [Prova Brasil] tem uma deficiência tremenda. Esse é o meu primeiro ponto de vista. Mas eu respeito a deficiência de um instrumento como esse. Porque eles também estão priorizando o primeiro passo de um processo. (Secretário de Educação) (grifamos)

O secretário diz "respeitar" a deficiência do teste por considerar que estão sendo empreendidos os "primeiros passos" de um processo mais abrangente realizado num país enorme. E sugere estar aguardando possíveis refinamentos desse processo, mediante os quais os alunos com deficiência 
poderão ter seu desenvolvimento escolar apreciado por meio de instrumentos mais "pertinentes" às suas especificidades. Esclarece, "refinamentos" são incumbências da esfera local, "eu acho que isso é responsabilidade do município. O MEC não vai dar conta disso. Serão os municípios que farão isso, porque é lá que as coisas acontecem, é na escola que as coisas estão acontecendo". (Secretário).

Trata-se da defesa explícita da lógica sobre a qual se assentam os processos de municipalização discutidos por Azevedo (2002), Oliveira (2009) e Cury (2002). Estes alertam para as diferenças - por vezes abissais entre os municípios brasileiros, que influenciam sobremaneira a capacidade de formular e implementar políticas e programas próprios, e viabilizar a implementação de programas e políticas nacionais.

Os alunos com deficiência da rede municipal de Sobral parecem "participar" da Prova Brasil. Vários sujeitos da pesquisa, entretanto, pronunciaram-se contrários a essa participação e, assim, sugeriram a necessidade de constituição de avaliações específicas para os alunos com deficiência.

O secretário de Educação afirmou que iniciativas de Educação Especial não foram uma preocupação inicial da SME no início do projeto . "No decorrer dos anos foram realizadas ações de refinamento dos processos e os links puderam ser estabelecidos". Ações de Educação Especial parecem ser um desses links; e as iniciativas de avaliação dos processos educacionais desses alunos se apresentam como um caminho a ser trilhado pela SME.

O diretor da Escola B discutiu a participação dos alunos com deficiência no teste nacional considerando o dilema inclusão versus exclusão. Essa participação significa, para o diretor, tratamento desigual, por isso, insiste na necessidade de um processo específico, e ao mesmo tempo amplo, que dispare a elaboração de uma política municipal de Educação Especial. O diretor da escola A e a coordenadora da escola $B$ também anuem à proposta de uma avaliação específica, enxergando-a como oportunidade de perceber o "progresso da criança dentro da proposta [de educação inclusiva]" e, assim, de promover uma avaliação mais pertinente. Esta coordenadora insistiu na necessidade da avaliação funcionar como instrumento orientador das práticas pedagógicas destinadas aos alunos com deficiência.

São encontradas, assim, práticas de avaliação de educação inclusiva que podem nos levar a discutir, ainda, os mecanismos de acesso e participação de estudantes com deficiência no contexto escolar. 


\section{Considerações finais}

As avaliações em larga escala recebem críticas por ficarem centradas no produto, ou seja, no desempenho dos estudantes. Isto limita o potencial mais reflexivo que a avaliação pode ter para colaborar com a melhoria do ensino. Assim, como afirmamos anteriormente, em índices como o IDEB, uma análise sobre os processos educativos são preteridos em função do cálculo para aferir os produtos.

Embora as críticas possam ser realizadas, a educação inclusiva pressupõe uma participação ampla dos alunos considerados grupo atendido pela Educação Especial em todas as atividades desenvolvidas pela escola, inclusive em processos avaliativos.

Na realidade investigada uma determinada municipalidade mostra como lida com o desafio dos processos de avaliação em larga escala quando voltados aos alunos com deficiência matriculados naquela rede de ensino.

Podemos inferir que na realidade estudada a avaliação coloca em xeque todo o processo de escolarização vivenciado pelas crianças. A existência do subterfúgio que cria as "crianças da margem" mostra os requintes dos processos excludentes recorrentes nos sistemas escolares. Os alunos, considerados clientela da Educação Especial mostram a agudez de uma inclusão precarizada que se personifica, por exemplo, nos processos "avaliativos" descritos no estudo de caso apresentado neste artigo.

\section{Referências}

ANDRÉ, M. E. D. A. de. Estudo de caso em pesquisa e avaliação educacional. Brasília: Liber Livro Editora, 2005.

AZEVEDO, J. M. L. de. Implicações da nova lógica de ação do Estado para a educação municipal. (p. 49-72). In Políticas públicas para a educação: olhares diversos sobre o período de 1995-2002. Revista Educação e sociedade: revista de ciência da educação. Campinas, v. 23, n. 80, set. 2002.

BARDIN, L. Análise de conteúdo. Lisboa: ed. 70, 1977.

BEYER, H. O. Inclusão e avaliação na escola: de alunos com necessidades educacionais especiais. Porto Alegre: Mediação, 2010.

BRASIL. Ministério da Educação. Plano de desenvolvimento da Educação: razões, princípios e programas. Brasília: MEC, 2007. 
CABRITO, B. G. Avaliar a qualidade em educação: avaliar o quê? Avaliar como? Avaliar para quê? Caderno Cedes, Campinas, v. 29, n. 78, p. 178200, mai/ago. 2009. CAMINI, L. A política educacional do PDE e do Plano de Metas Compromisso Todos pela Educação. Revista Brasileira de Política e Administração da Educação.v. 26, n. 3, p. 535-550. set./dez. 2010.

CASTRO, M. H. G. de. A institucionalização da política de avaliação da educação básica no Brasil. In: COLOMBO, S. S.; CARDIM, P. A. G. (Org.). In: Nos bastidores da educação brasileira: a gestão vista por dentro. Porto Alegre: Artmed, 2010 (p. 147-167).

CURY, C. R. J. A educação básica no Brasil. Educação e Sociedade, Campinas, v. 23, n. 80, set./2002, p. 168-200.

FERNANDES; T. L. G.; VIANA, T. V. Da exclusão à inclusão na avaliação da aprendizagem. In: VIANA; T. V.; CIASCA, M. I. F. L.; SOBRAL, A. E. B. Múltiplas dimensões em avaliação educacional. Fortaleza: Imprece, 2010.

FERREIRO, E. Reflexões sobre alfabetização. São Paulo: Cortez, 2001.

FRANCO, M. L. P. B. Análise de conteúdo. Brasília, 2. ed.: Liber Livro Editora, 2005.

MARTINS, G. de A. Estudo de caso: uma estratégia de pesquisa. 2. ed. São Paulo: Atlas, 2008.

MINAYO, M. C. de S. O desafio do conhecimento: pesquisa qualitativa em saúde. São Paulo: Hucitec, 2008.

MONTEIRO, K. R. A. Inclusão escolar e avaliação em larga escala: pessoas com deficiência na Prova Brasil. 122f. Dissertação (Mestrado em Educação). Universidade Católica de Santos, Santos, 2010.

OLIVEIRA, A. A. S.; CAMPOS, T. E. Avaliação em educação especial: o ponto de vista do professor de alunos com deficiência. Estudos em Avaliação Educacional, v. 16, n. 31, jan./jun. 2005. p. 51-77.

OLIVEIRA, R. P. de. Da universalização do ensino fundamental ao desafio da qualidade: uma análise histórica. Educação e Sociedade. v. 28, n. 100 Especial, p. 661-690, out./2007.

SILVA, T. T. O projeto educacional da nova direita e a retórica da qualidade total. In: Escola e S. A.: quem ganha e quem perde no mercado educacional do neoliberalismo. Brasília: CNTE, 1996.

Revista Educação Especial | v. 25 | n. 44, | p. 449-464 | set./dez. 2012

Santa Maria

Disponivel em: <http://www.ufsm.br/revistaeducacaoespecial> 
SOUSA, S. Z. Avaliação e gestão da educação básica: da competição aos incentivos. In: DOURADO, Luiz Fernandes (Org.). São Paulo: Xamã, 2009. p. 31-48.

STAKE, R. Investigación com estúdio de casos. Madrid: Morata, 1998.

\section{Notas}

${ }^{1}$ O presente estudo é um excerto da investigação "Política de educação inclusiva em tempos de IDEB: escolarização dos alunos com deficiência da rede de ensino de Sobral-CE", trabalho elaborado ao curso de Mestrado em Educação da Universidade Estadual do Ceará. Está articulada, ainda, ao Observatório da Educação do INEP que investigou as iniciativas de política educacional dos municípios de São Paulo, Mato Grosso do Sul e Ceará (coordenado na Universidade Estadual do Ceará pela Profa. Dra. Sofia Lerche Vieira) às quais se atribuiu contribuições para alterar o indicador IDEB nesses contextos.

2 O termo "resultados" na sentença quer dizer toda e qualquer "produção" acadêmica do aluno com deficiência proveniente da mediação realizada pelos professores e observada na escola.

${ }^{3}$ Censo Demográfico 2010/IBGE.

${ }^{4}$ Os Ferreira Gomes e seus aliados.

${ }^{5}$ Assumindo o percentual de $38,29 \%$ das matrículas, portanto. Neste número, estão incluídas 16.954 matrículas na rede estadual (rural e urbana) de ensino, e 12.060 matrículas na rede privada (urbana), nos níveis e modalidade ofertadas naquele Município.

${ }^{6}$ O IDEB de Sobral em 2011 foi de $7,3$.

${ }^{7}$ Nesta coluna estão incluídos os alunos do $5^{\circ}$ ano do EF.

${ }^{8} \mathrm{O}$ Total 1 é a soma de todos os alunos matriculados no ensino fundamental, de $1^{\circ}$ ao $9^{\circ}$ anos.

9 Sistema Permanente de Avaliação Educacional do Ceará, criado em 1992, no governo Cid Gomes. Por fugir aos objetivos deste estudo, não discutiremos os processos desta avaliação estadual.

${ }^{10}$ Lei Municipal $n^{\circ} 342$, de $05 / 03 / 2002$, instituiu gratificação mensal para os professores alfabetizadores da rede municipal. O Decreto $n^{\circ} 588$, de 28/10/2003, regulamentou a lei, determinando que o professor alfabetizador pode ter o valor da gratificação reduzido caso a meta de alfabetização prescrita na Portaria $n^{\circ}$ 042/200 e verificada por meio da avaliação externa não fosse obtida.

11 O "Projeto" de Educação de Sobral se inicia a partir dos anos 2000.

\section{Correspondência}

Ana Paula Lima Barbosa Cardoso - Rua Batista de Oliveira, 1050, apt 201 - Cocó, CEP: 60176-030 - Fortaleza, Ceará.

E-mail: cardoso.paula@uol.com.br - ritafora@hotmail.com

Recebido em 17 de setembro de 2012

Aprovado em 27 outubro de 2012

Revista Educação Especial | v. 25 | n. 44, | p. 449-464 | set./dez. 2012 